\title{
Thermal resistance of viscose socks
}

\author{
Beti Rogina-Car, Zenun Skenderi, Zlatko Vrljičak \\ Sveučilište u Zagrebu Tekstilno-tehnološki fakultet, Prilaz baruna Filipovića 28, 10000 Zagreb, \\ Hrvatska
}

E-mail: beti.rogina-car@ttf.hr

Original scientific paper

UDK: 687.254.8.021-026.65-055.1:677.463

Abstract:

DOI: $10.34187 / k o .68 .3 .6$

Men's viscose socks size 42 were designed and manufactured on an automatic sock knitting machine with a cylinder diameter of $95 \mathrm{~mm}\left(3 \frac{3 / 4}{4} \mathrm{inches}\right)$ which knits with 108 needles. Socks were manufactured of 20 tex viscose yarn, 156 and 220 dtex filament PA 6.6 yarn and 25 tex cotton yarn in multiple plated single jersey structure. The sock cuff contained an interlaced elastane yarn. Sock weight and sock thickness were determined, the height of the sock leg, the length of the sock foot and half of the leg circumference and half of the foot circumference were measured. Thermo physiological sock properties were determined by measuring thermal resistance on a thermal foot manikin. The sock structure under the same knitting conditions depends on the number of yarns, yarn type, the type of raw material (viscose, cotton, PA) and yarn count. Finer yarns provide higher stretchability in the part of the sock leg in the wale direction. The viscose socks with an added coarser cotton yarn and a coarser PA 6.6 yarn had the highest thermal resistance, while the viscose yarns with only an added PA 6.6 yarn had the lowest thermal resistance.

\section{Keywords:}

socks, viscose, PA, thermal resistance, thermal foot

\section{Introduction}

The human body has about three million sweat glands on the skin surface. During the daytime due to human activities up to $40 \mathrm{~g}$ of skin fat and $0.5-1$ liters of sweat are excreted from the skin surface. In various human activities, clothing must ensure thermophysiological balance or comfort. Wear comfort is the interaction between the body, garment system made up of layers of textile material, air and environment. Thermophysiological wear comfort is also affected by the raw material composition and structural parameters of the garment [1-4]. Knitwear worn on the body, such as stockings and socks, underwear, T-shirts, pajamas, etc., must allow the sweat to evaporate and remove moisture from the body as efficiently as possible. The specific structure of the knitwear gives the garment a porosity that allows the passage of water vapor through the pores of the knitwear into the environment [1-4]. Human comfort is influenced by factors that can be divided into three categories:

a) user-specific factors (metabolism, age, fitness, activity),

b) fiber type, yarn type, fabric design, garment design and construction; and

c) external conditions (humidity, temperature, air speed) [4].

Socks are made in different shapes and sizes depending on their purpose. They are a specific textile product that is often made of at least three substantially different raw materials, e.g. cotton, PA and elastane. The most common raw materials for making socks are cotton or wool single or ply yarns. The elasticity of the socks is achieved by interlacing a PA filament yarn with a significantly higher breaking elongation (about $30 \%$ ) with the basic yarn. In the socks manufacturing process the yarn is fed into the knitting zone in the stretched state. After stitch formation the yarns contract resulting in the knitted fabric contraction from 20 to $40 \%$ and a sock made. This kind of knitted fabric contraction is possible due to the elasticity of the PA filament. Greater elasticity is required in the sock cuff, so an elastane thread (elastic band) is interlaced in this section with the function to hold the sock in place on the leg [5-8].

Tensile properties of socks include extension of the knitted fabric in the course direction. Wale spacing $(A)$ increases and course spacing (B) decreases, i.e. the height of the knitted fabric decreases. The intersection between the wale spacing $(A)$ and the course spacing $(B)$ in the shrunken sock creates the point $M$ (Fig. 1). In transverse extension of the sock the wale spacing (A) increases, and the course spacing (B) decreases, while the point $S$ marks the moment of the knitted fabric breakage. In the case of sock extension in the wale direction the greatest course spacing (Bmax) and the smallest wale spacing (Amin) are obtained. The mentioned values Bmax and Amin create the point $R$ whose value is approximately equal to

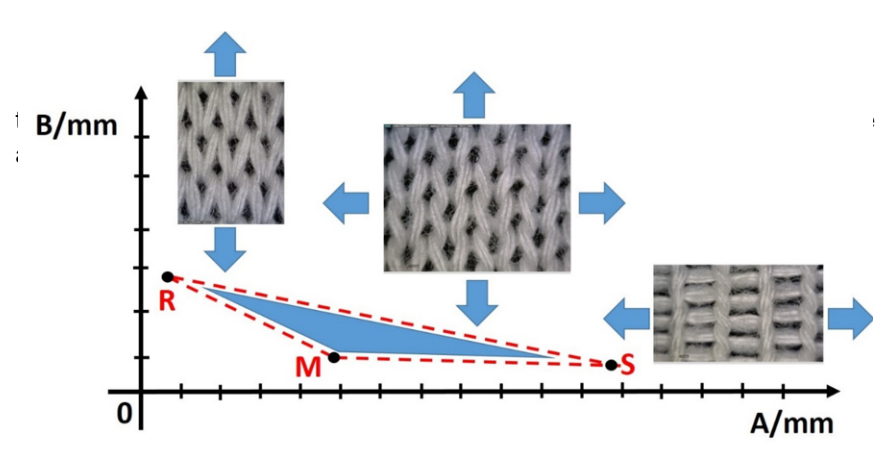

Fig. 1 Transverse and longitudinal extension of the knitted fabric in the sock

Thermal resistance can be defined as the ability of the material to provide resistance to the heat flow through the material. Most of the literature studies the thermophysiological properties of the knitted fabric used to make socks, not the thermophysiological properties of the manufactured socks [10,11]. Research on thermal conductivity of 30 types of knitted fabrics made of different fiber types, with or without an addition of textured PA and elastane threads (LYCRA) was conducted by a group of authors (Čiukas et al.). The values of the thermal conductivity coefficient for 30 types of knitted fabrics ranged from 0.028 to $0.0644 \mathrm{~W} /\left(\mathrm{m} \times{ }^{\circ} \mathrm{C}\right)$, while the values of thermal resistance ranged from 0.0119 to $0.0401 \mathrm{~m}^{2} \times{ }^{\circ} \mathrm{C} \times$ $W^{-1}[10,11]$. The results of the study by Gun et al. reveal that the interlaced thread has a significant effect on thermal conductivity [12]. The thermal resistance of the knitted fabric depends on the thickness and weight of the knitted fabric as well as on its porosity [13].

Heat transfer by convection causes the air to flow around the body. This fact depends on the difference between skin and air temperature and air flow rate. Under normal conditions, about $30 \%$ of heat is exchanged by heat convection between the body and the environment. The amount of heat transferred by conduction is much smaller than the amount transferred by convection $[15,16]$. Heat transfer by conduction becomes important when persons come in contact with cold objects [17]. Heat transfer by conduction accounts for $15 \%$ of the total heat transfer, depending on the object and material in contact with the skin [18]. In human beings, heat is transferred by sweat evaporation. By increasing the environmental temperature above the pleasant body temperature leads to a stronger sweat secretion, causing a sudden increase in body heat loss [19]. Heat transfer by evaporation from the skin surface depends on the amount of moisture on the skin and the difference between the water vapor pressure on the skin and the environment [17]. Under normal conditions evaporation from the skin surface ranges from 450 to $600 \mathrm{ml}$ per day, i.e. heat loss ranges from 50 to $70 \mathrm{~kJ} / \mathrm{h}[20]$.

The objective of this study is to investigate how different raw material compositions of yarns added to viscous yarns in socks affect thermal resistance, as one of the main thermophysiological comfort parameters. 


\section{Experimental part}

\section{1. Materials and methods}

For the purposes of this study presented in the paper sock samples made of viscose ring yarns with the addition of cotton and/or PA yarn with a different yarn count were used (Table 1).

Tab. 1 Abbreviations and description of sock samples

\begin{tabular}{|c|c|c|c|c|}
\hline \multirow{2}{*}{\multicolumn{2}{|c|}{ Samples }} & \multicolumn{2}{|c|}{ Yarns } & \multirow{3}{*}{$\begin{array}{l}\text { Description of the sample } \\
\text { Knitted with four yarns in a row: } \\
3 \times \text { VR + } 1 \text { x PA 6.6. } 156 \text { dtex }\end{array}$} \\
\hline & & PA 6.6., dtex & Different yarn count, tex & \\
\hline \multirow{3}{*}{$\begin{array}{l}\text { VR - viscose ring yarns } \\
\text { with the addition of cotton } \\
\text { and/or PA yarn with a } \\
\text { different yarn count; } \\
\text { PK- cotton ring yarn }\end{array}$} & VR_A & 156 & 3 VR $x 20$ tex & \\
\hline & VR_B & 220 & 3 VR $\times 20$ tex & $\begin{array}{l}\text { Knitted with four yarns in a row: } \\
3 \times \text { VR }+1 \text { x PA 6.6. } 220 \text { dtex }\end{array}$ \\
\hline & VR_C & 220 & $\begin{array}{l}2 \mathrm{VR} \times 20 \text { tex } \\
1 \mathrm{PK} \times 25 \text { tex }\end{array}$ & $\begin{array}{c}\text { Knitted with four yarns in a row: } \\
2 \times \text { VR }+1 \times \text { PK } 25 \text { tex }+1 \times \text { PA 6.6. } 220 \\
\text { dtex }\end{array}$ \\
\hline
\end{tabular}

The sock mass was measured using an analytical balance. The average sock mass was determined by the individual weighing of four socks and on the basis of individual measurements the average mass of one sock was obtained [5]. The sock thickness was measured using a thickness gauge with three little metal plates. One plate was inserted into the sock leg, and the other two plates were placed on the outside of the sock, and the thickness of the "sandwich" was measured. The thickness of one plate was $1.00 \mathrm{~mm}$. Ten measurements were carried out, and the average thickness of the knitted sock was calculated [5]

The sock dimensions were measured in such a way that they were straightened out on a flat surface, and the length measurement instrument was used to measure a certain length with a reading accuracy of $1 \mathrm{~mm}$. [5]. The method of measuring sock dimensions is shown in Figure 2.

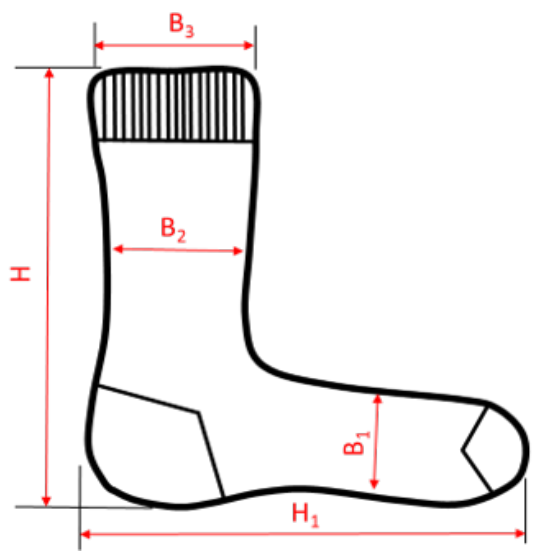

Fig. 2 Sock shape with main measurements, $\mathrm{H}$ - sock length, $\mathrm{H} 1$ - length of the sock foot, B1- half the foot circumference, B2 - half the circumference of the length $\mathrm{H}, \mathrm{B} 3$ - half the circumference at the ankle height [5]

\section{2. Determination of thermal resistance on the thermal foot manikin}

Thermal resistance of socks was studied on the thermal foot manikin which is divided into 13 segments. Each segment is separately heated at $35^{\circ} \mathrm{C}[21,22]$. Figure 3 shows the interface of the thermal foot manikin control unit with data display.

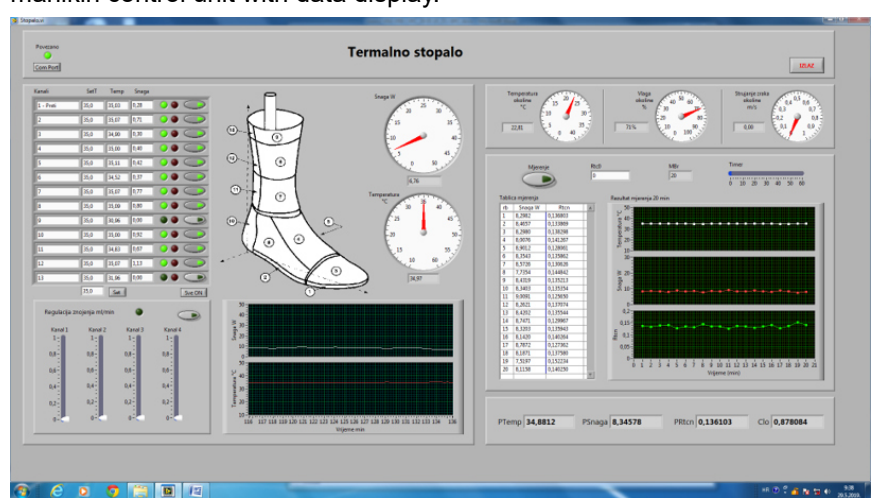

Fig. 3 Control unit of the thermal foot manikin system
All socks, regardless of minor differences in length, were placed on the thermal foot manikin, so as to cover the whole measuring, i.e. all segments (Tab. 3, Fig. 5). The measurement procedure on the thermal foot manikin was carried out by placing a $100 \%$ basic cotton sock on the thermal foot manikin. The system was then stabilized for 20 - 30 minutes, after which $R_{c t 0}$ was measured. A sock sample was placed, and a 20 - 30 minute re-stabilization period was applied after which $R_{\text {ctu }}$ was measured. This procedure was repeated for each sock sample. Thus, the thermal foot manikin measures the resistance of the device with the basic sock $\left(R_{c t 0}\right)$ and the total resistance of the device, the basic sock and the sample $\left(R_{c t u}\right)$.

The thermal resistance of the tested sock sample $R_{c t}$ is obtained from the difference $\mathrm{R}_{\mathrm{ctu}}$ and $\mathrm{R}_{\mathrm{ct} 0}$ according to the expression:

$$
R_{c t}=R_{c t u}-R_{c t o}(1)
$$

The measured thermal resistance (during static measurement) is the sum of the conduction and radiation thermal resistances. The convection thermal resistance, during static measurement (without motion), on the thermal foot manikin is low and is neglected. In cases where convection is significant, it is necessary to maintain the air flow rate in the narrow specified area [21-24]. Natural convection was used for these measurements.

Since a certain amount of extension of socks occurs after they have been placed on the thermal foot manikin, it is necessary to define how this extension will be measured and calculated. Figures 4 and 5 show the procedure for marking samples and measuring the parameters of unstretched and stretched socks.

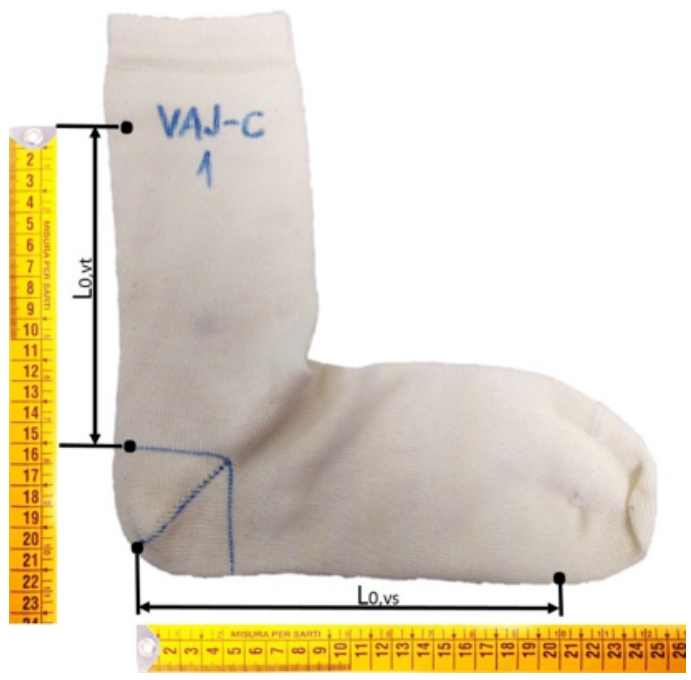

Fig. 4 Sample marking for measuring geometrical parameters of the unstretched sock

First, the marked lengths on the leg and foot of the unstretched sock are measured (Fig. 4) $\mathrm{L}_{0 \text { vs }}(150 \mathrm{~mm})$ and $\mathrm{L}_{0 \mathrm{vt}}(200 \mathrm{~mm})$, respectively. The sample is then placed on the thermal foot manikin and the elongation of the sock is measured along the curve $L_{1, v s} i L_{1, v t}$ (Fig. 5). 


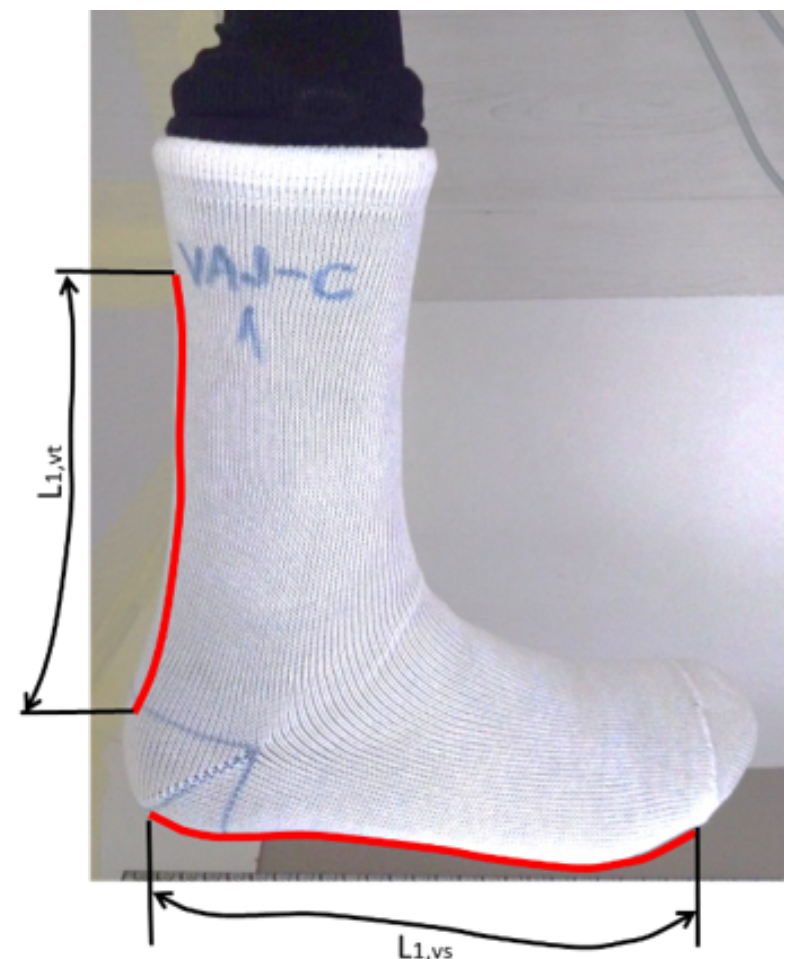

Fig. 5 Measurements of socks extension parameters along the thermal foot curve

Tab. 2 Knitted fabric thickness of the sock and mass of socks samples
The relative extension of the sock on the part of the foot $\varepsilon_{v s}(\%)$ is the extension in the wale direction, which occurs by placing the sock on the thermal foot manikin, and it is calculated according to the expression:

$$
\varepsilon_{v s}=\frac{\Delta L_{v s}}{L_{0, v s}}=\frac{L_{1, v s}-L_{0, v s}}{L_{0, v s}} \cdot 100
$$

The relative extension on the part of the sock leg $\varepsilon_{\mathrm{vt}}(\%)$ is also calculated by measuring the extension in the wale direction on the sock leg using the expression:

$$
\varepsilon_{v t}=\frac{\Delta L_{v t}}{L_{0, v t}}=\frac{L_{1, v t}-L_{0, v t}}{L_{0, v t}} \cdot 100
$$

where: $L_{v s}, L_{v t}$ - the absolute extension of socks in the foot and the leg, $L_{1, v s}, L_{1, v t}$ - the measured values after placing the sock on the thermal foot manikin in the wale direction, $\mathrm{L}_{0, v s}, \mathrm{~L}_{0, \mathrm{vt}}$ - initial values of measuring the sock in the wale direction in the foot and the leg before placing the sock on the thermal foot manikin $\left(\mathrm{L}_{0, v s}=150 \mathrm{~mm}, \mathrm{~L}_{0, \mathrm{vt}}=200 \mathrm{~mm}\right)$.

\section{Results and discussion}

The mass and thickness of the socks were determined, the height of the leg of the sock, the length of the foot of the sock, and half the leg circumference and half the circumference of the foot of the sock were measured. The characteristics of the sock sample are shown in Tables 2 and 3. Five measurements were performed at different locations on each of 4 socks per sample. The deviation from the mean value was determined with a reliability of $95 \%$.

\begin{tabular}{|c|c|c|}
\hline Samples & Mass of the sock, g/piece & Sock thickenss, mm \\
\hline VR_A & $18.7 \pm 0.0$ & $1.20 \pm 0.02$ \\
\hline VR_B & $20.9 \pm 0.1$ & $1.28 \pm 0.01$ \\
\hline VR_C & $22.7 \pm 0.0$ & $1.37 \pm 0.02$ \\
\hline
\end{tabular}

Tab. 3 Dimensions of socks samples

\begin{tabular}{|c|c|c|c|c|c|}
\hline Samples & $\mathrm{H}, \mathrm{mm}$ & $\mathrm{H}_{1}, \mathrm{~mm}$ & $\mathrm{~B}_{1}, \mathrm{~mm}$ & $\mathrm{~B}_{2}, \mathrm{~mm}$ & $\mathrm{~B}_{3}, \mathrm{~mm}$ \\
\hline VR_A & $235 \pm 3$ & $274 \pm 2$ & $92 \pm 1$ & $87 \pm 0$ & $85 \pm 0$ \\
\hline VR_B & $233 \pm 5$ & $272 \pm 2$ & $93 \pm 1$ & $88 \pm 1$ & $86 \pm 1$ \\
\hline VR_C & $242 \pm 3$ & $273 \pm 4$ & $93 \pm 1$ & $89 \pm 1$ & $85 \pm 1$ \\
\hline
\end{tabular}

The results of the calculated relative extension according to expressions ( 2 and 3 ) and the results of thermal resistance of the sock samples on the thermal foot manikin are shown in Table 4.

Tab. 4 Results of the extension of socks sample on the thermal foot manikin

\begin{tabular}{|c|c|c|c|c|c|c|c|c|}
\hline Samples & $\mathrm{L}_{1, \mathrm{vs}}, \mathrm{mm}$ & $\mathrm{SD}, \mathrm{mm}$ & $\mathrm{CV}, \%$ & $\varepsilon_{\mathrm{vs}}, \%$ & $\mathrm{~L}_{1, \mathrm{v}}, \mathrm{mm}$ & $\mathrm{SD}, \mathrm{mm}$ & $\mathrm{CV}, \%$ & $\varepsilon_{\mathrm{vt}} \%$ \\
\hline VR_A & 207.7 & 3.79 & 1.82 & 3.85 & 166.3 & 4.04 & 2.43 & 10.57 \\
\hline VR_B & 204.0 & 1.41 & 0.69 & 2.00 & 166.0 & 4.24 & 2.56 & 10.67 \\
\hline VR_C & 204.3 & 3.06 & 1.50 & 2.15 & 158.3 & 2.52 & 1.60 & 5.53 \\
\hline
\end{tabular}

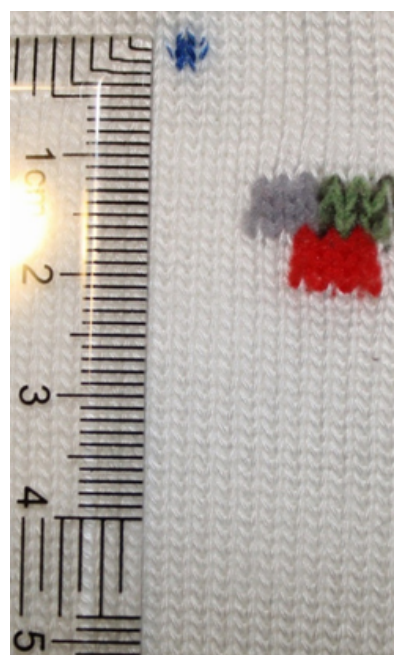

Fig. 6 Structure of the unstretched (left) and the stretched sock on the thermal foot manikin (right)
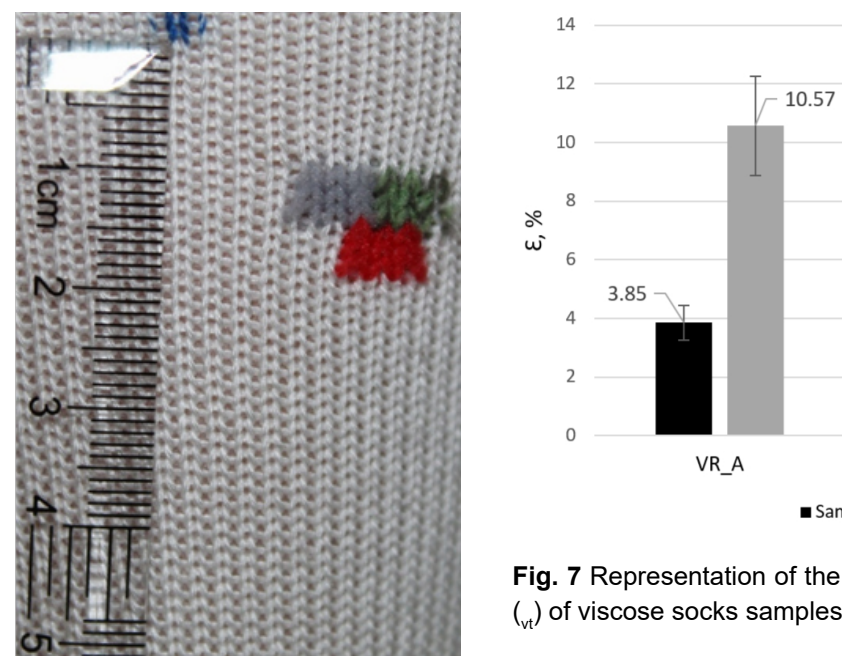

VR_A $\left({ }_{v 1}\right)$ of viscose socks samples

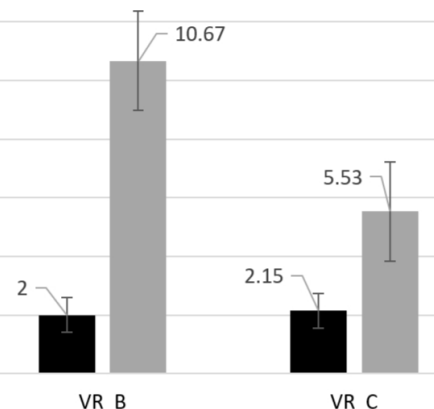

- Sample $\varepsilon \mathrm{H}, \%$ ॥ Sample $\varepsilon \mathrm{V}, \%$

Fig. 7 Representation of the extension of the foot part $\left({ }_{\mathrm{vs}}\right)$ and the leg part

When measuring thermal resistance, the samples were left for 24 hours under standard conditions at a temperature of $20 \pm 2^{\circ} \mathrm{C}$ and a relative 
humidity of $65 \pm 5 \%$ before testing. Three measurements were performed for each sample, and the mean value, standard deviation, and coefficient of variation were calculated (Table 5).

Tab. 5 Results of thermal resistance $\left(R_{c t}\right)$ for samples of different socks

\begin{tabular}{|c|c|c|c|}
\hline Samples & $\mathrm{R}_{\mathrm{ct},} \mathrm{m}^{2}{ }^{\circ} \mathrm{C} \mathrm{W}^{-1}$ & $\mathrm{SD}, \mathrm{m}^{2}{ }^{\circ} \mathrm{CW}^{-1}$ & $\mathrm{CV}, \%$ \\
\hline VR_A & 0.0139171 & 0.002 & 12.9 \\
\hline VR_B & 0.0126739 & 0.002 & 18.8 \\
\hline VR_C & 0.0193540 & 0.003 & 17.6 \\
\hline
\end{tabular}

$\mathrm{R}_{\mathrm{ct}}, \mathrm{m}^{2}{ }^{\circ} \mathrm{C} \mathrm{W}^{-1}$

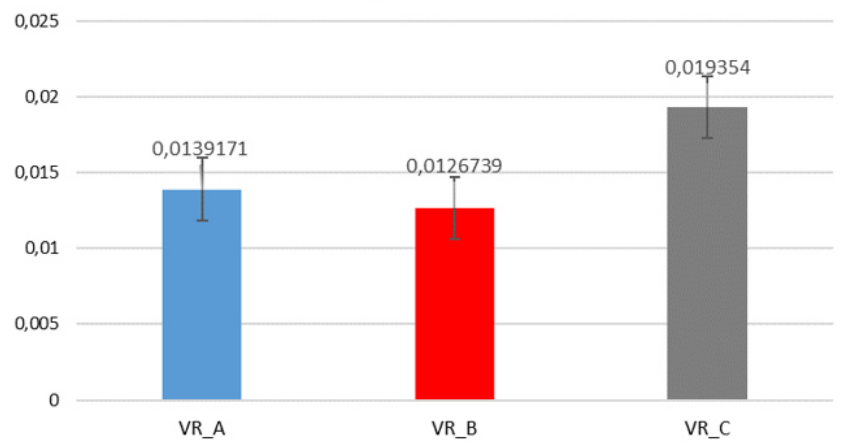

Fig. 8 Thermal resistance for samples of different socks

The sample VR_C has a relatively roughest knit structure relative to the other two sock samples, because the two yarns in the sock structure are coarser, the cotton yarn is of 25 tex and the PA yarn is of 220 dtex (Table 1). The consequence of this is the proportional maximum thickness of the knitted fabric of sample VR_C $(1.37 \mathrm{~mm})$ and proportionally the highest mass of the sock $22.7 \mathrm{~g} / \mathrm{pc}$ (Table 2 ). The VR B sample contains a coarser PA yarn than the VR_A in its structure and consequently greater thickness $(1.28 \mathrm{~mm})$ and sock mass $(20.9 \mathrm{~g} / \mathrm{pc})$.

The finer yarns in the sock samples (VR_A and VR B) caused higher extensions measured on the thermal foot manikin in the sock leg in the wale direction ( 10.57 or $10.67 \%$ ) compared to the knitted fabric made of relatively coarser yarns of the sample VR_C (5.53\%) (Table 4). Thermal resistance for all sock samples ranged from 0.0127 to $0.01944 \mathrm{~m}^{2}{ }^{\circ} \mathrm{C} \mathrm{W}^{-1}$. The lowest value of thermal resistance was obtained for sock samples VR B made of three 20 tex visose yarns and one 220 dtex PA yarn, while the highest values were found in the sample VR_C $\left(0.0194 \mathrm{~m}^{2}{ }^{\circ} \mathrm{C} \mathrm{W}^{-1}\right)$ which had the relatively greatest thickness and highest mass of the sock made of two 20 tex viscose yarns, one 25 tex cotton yarn and one 220 dtex PA yarn.

\section{Conclusion}

The sock structure under the same knitting conditions depends on the number of yarns, yarn type (ring-spun, rotor-spun air-jet spun), the type of raw material (viscose, cotton, PA) and yarn count. The extension of socks was determined on the thermal foot manikin during measuring thermal resistance of the socks made of three 20 tex viscose yarns with addition of 156 or 220 dtex PA yarns, and it was higher (10.27 to $10.67 \%$ ) than the extension of the socks made of 2 viscose yarns with addition of one 25 tex cotton yarn and one 220 dtex PA yarn (5.53\%). Coarser yarns (cotton and PA) caused greater thickness and mass and lower extension in the wale direction on the sock leg.

The highest thermal resistance had the socks made of viscose yarns with addition of coarser cotton yarn and coarser PA 6.6 yarn (0.0194 $\mathrm{m}^{2}{ }^{\circ} \mathrm{C} \mathrm{W}^{-1}$ ), while the lowest thermal resistance was found in the socks made of viscose yarns with addition of only PA 6.6 yarn with a count of 156 or 220 dtex $\left(0.0127 \mathrm{~m}^{2}{ }^{\circ} \mathrm{C} \mathrm{W}^{-1}\right)$

\section{Funding}

This work was funded by the Croatian Science Foundation based on Project IP-2016-06-5278.

\section{References}

[1] Morishita R., Saito M., Tsuchida K., Harada T.: Studies on Micro-climate within Clothing and the Equipment for its Evaluation, Research Institute, Toyobo Co Ltd, 1993
[2] Hatch L. K.: Textile Science, University of Arizona, Tucson, West Publishing company, (1993) 27-43.

[3] Mecheels J.: Körper-Klima-Kleidung: Wie funktioniert unsere Kleidung?, Schiele \& Schon, Berlin, 1998

[4] Mangat A. M. M.: Clothing Comfort: A Combination of Objective and Subjective Evaluations, Technical University Liberec, https:// www.scribd.com/doc/30439784/Introduction-to-Clothing-Comfort pristupljeno 15.12.2019

[5] Vrljičak Z., Pavlović Ž.: Dimensional instability of socks. Tekstil 63 (2014) 1-2, 27-40.

[6] Modig N.: Hosiery Machines, Meisenbach, Bamberg, 1988

[7] Bašnec I.: Proces izrade finih ženskih čarapa, Tekstil 43 (1994) 5, 255259

[8] Spenser D.: Knitting Technology, Pergamon Press, Oxford, 1983

[9] Vrljičak Z.: Utjecaj sile u niti na ulazu u pletaći sistem na mehanička svojstva desno-desnog kulirnog pletiva, Tekstil 39 (1990) 9, 544-549

[10] Čiukas R., Abramavičiūtè J., Kerpauskas P.: Investigation of the Thermal Properties of Socks Knitted from Yarns with Peculiar Properties. Part I. Thermal Conductivity Coefficient of Socks Knitted from Natural and Synthetic Textured Yarns, Fibres \& Textiles in Eastern Europe 18 (2011) 3, 89 - 93

[11] Čiukas R., Abramavičiūtè J., Kerpauskas P.: Investigation of the Thermal Properties of Socks Knitted from Yarns with Peculiar Properties. Part II: Thermal Resistance of Socks Knitted from Natural and Stretch Yarns, Fibres \& Textiles in Eastern Europe 19 (2011) 3, 64 $-68$

[12] Gun A. D., Alan G., Macit A. A.: Thermal properties of socks made from reclaimed fibre, The Journal of The Textile Institute 107 (2016) 9, 1112 $-1121$

[13] Čubrić Salopek I., Skenderi Z., Mihelić-Bogdanić A., Andrassy M.: Experimental study of thermal resistance of knitted fabrics. Experimental thermal and fluid science 38 (2012), 223-228

[14] Kroemer K. H. E., Grandjean E.: Prilagođavanje rada Čovjeku. Ergonomski priručnik, Naklada Slap, 1999., Zagreb

[15] Havenith G.: Clothing and thermoregulation. Textiles and the Skin, in book Current problems in Dermatology. Wigger-Alberti W (eds), Karger Verlag, Basel 31 (2002), 35-39

[16] Havenith G.: Individualized model of human thermoregulation for the simulation of heat stress response. Journal of Applied Physiology 90 (2001), 1943-1945

[17] Skenderi Z., Salopek Čubrić I., Srdjak M.: Water Vapour Resistance of Knitted Fabrics under Different Environmental Conditions. Fibres \& Textiles in Eastern Europe 2 (2009) 73, 72-75

[18] Fukazawa T., Lee G., Matsuoka T., Kano K., Tochihara Y. Heat and water vapor transfer of protective clothing systems in a cold environment, measured with a newly developed sweating thermal manikin. European Journal of Applied Physiology 92 (2004), 645-648

[19] Salopek I., Skenderi Z., Srdjak M.: The knitted fabric comfort - aspect of fabric hand. Melliand Textilberrichte 6 (2007), 426-428

[20] Fiala D., Lomas K. J., Stohrer M.: A computer model of human thermoregulation for a wide range of environmental conditions: the passive system. Journal of Applied Physiology 87 (1999), 1957-1972

[21] Foot Manikin, Technical specifications, Model FM 005-08, Version1.0, March 2010, UCS, Slovenia.

[22] Skenderi Z., Mihelić-Bogdanić A., Mijović B.: Termofiziološka udobnost nošenja obuće, Koža i obuća 66 (2017) 3, 12-21

[23] Kulišić P.: Mehanika i toplina, IV izdanje, Školska knjiga, Zagreb, 1989

[24] Qengel Y.A., Boles M.A: Thermodynamics, An Engineering Approach, third edition, WCB/McGraw-Hill, 1998, 103-111 